Kari Korttila MD PhD, Pontus L. Östman MD, Evelina Faure MD, Jeffrey L. Apfelbaum MD, Mona Ekdawi MD, Michael F. Roizen MD

\title{
Randomized compari- son of outcome after propofol-nitrous oxide or enflurane-nitrous oxide anaesthesia in operations of long duration
}

A randomized, prospective, comparative study was performed to evaluate induction characteristics, haemodynamic changes and recovery in 60 ASA I-II patients undergoing mainly gynaecological laparotomies with either propofol or thiopentone-enflurane anaesthesia. The propofol group in $=$ 30) received $2 \mathrm{mg} \cdot \mathrm{kg}^{-1}$ propofol for induction of anaesthesia followed by propofol infusion. The thiopentone-enflurane group $(n=30)$ received thiopentone $4 \mathrm{mg} \cdot \mathrm{kg}^{-1}$ for induction followed by enflurane $(0.5-2$ per cent). All patients received nitrous oxide (66 per cent)) in oxygen begun one minute after tracheal intubation, and fentanyl ( $\left.1.5 \mu \mathrm{g} \cdot \mathrm{kg}^{-1}\right)$ four minutes prior to induction. Other drugs administered during or after anaesthesia were similar among the groups. Haemodynamic measurements were similar between propofol and enflurane groups except after tracheal intubation when the mean arterial pressure was lower in the propofol group $(P<0.05)$. The propofol group had significantly less $(P<0.01)$ emesis in the recovery room than the enflurane group. The propofol group experienced significantly less $(P<0.05)$ dizziness, depression/sadness and hunger than the enflurane group in the postoperative period as assessed

\section{Key words}

ANAESTHETICS, INTRAVENOUS: propofol, thiopentone; ANAESTHETICS, VOLATILE: enflurane; ANAESTHETIC TECHNIQUES: general; COMPLICATIONS: nausea, vomiting; RECOVERY: assessment.

From the Department of Anesthesia and Critical Care, The University of Chicago, Chicago, Illinois.

Address correspondence to: Dr. P. Östman, Department of Anesthesia, The University of Iowa Hospital and Clinics, lowa City, Iowa 52242.

The study was supported in part by Stuart Pharmaceuticals, Wilmington, Delaware. with a visual analogue questionnaire. We conclude that pro. pofol provided better outcome than enfurane in terms of these nonvital but annoying outcome measures after relatively long intra-abdominal operations.

Interest in intravenous (IV) anaesthesia has been augmented by the introduction of propofol, the kinetics of which allow induction and maintenance of anaesthesia with rapid recovery of consciousness. ${ }^{1}$ Propofol is effective for maintenance of anaesthesia when given IV as repeated bolus injections or as a continuous infusion. ${ }^{2-4}$ Propofol has been compared favorably with other IV or inhalational anaesthetic methods in operations of short duration ${ }^{5}$ however, particular attention has not been focused on the comparative benefits and risks of propofol anaesthesia with inhalational anaesthesia in operations of longer duration. This randomized, comparative study examined the safety and efficacy as well as the speed and quality of recovery from propofol or thiopentoneenflurane anaesthesia in patients undergoing mainly gynaecological laparotomies.

\section{Methods}

The protocol was approved by the University of Chicago Clinical Investigation Committee and written informed consent was obtained from 60 unpremedicated patients (59 women, one man) with ASA physical status I or II. The women were scheduled for gynaecological laparotomies. Pregnancy was excluded by a negative pregnancy test before surgery. No patient had a history of allergy to medications or evidence of hepatic, renal, haematological, cardiovascular, respiratory, or metabolic disease.

Patients entered the preanaesthesia care unit without any premedication and were randomized to receive either propofol (2,6-diisopropylphenol, Diprivan, Stuart Phar- 
maceuticals, Wilmington, Delaware), or thiopentoneenflurane anaesthesia. Patients did not know which anaesthetic agent was to be administered. Intravascular access was established under local anaesthesia with an 18 SWG cannula in a vein on the dorsum of the hand or wrist. An intravenous infusion was started with dextrose five per cent in water. Immediately before induction of anaesthesia, all patients received d-tubocurarine $3 \mathrm{mg}$, glycopyrrolate $0.2 \mathrm{mg}$, and fentanyl $1.5 \mu \mathrm{g} \cdot \mathrm{kg}^{-1} \mathrm{IV}$. Four minutes later, anaesthesia was induced with either propofol $2 \mathrm{mg} \cdot \mathrm{kg}^{-1}$ or thiopentone $4 \mathrm{mg} \cdot \mathrm{kg}^{-1} \mathrm{IV}$ over a period of $30 \mathrm{sec}$. Oral tracheal intubation was performed 60-90 sec after succinylcholine injection $\left(1.5 \mathrm{mg} \cdot \mathrm{kg}^{-1}\right)$. Anaesthesia was maintained with either propofol infusion or enflurane (0.5-2 per cent) in nitrous oxide $\left(\mathrm{N}_{2} \mathrm{O}\right) 66$ per cent and oxygen started $60 \mathrm{sec}$ after tracheal intubation. During induction of anaesthesia, the times for loss of consciousness and loss of eyclid reflex as well as any pain at the IV site were recorded. The first ten patients randomized to the propofol group, received propofol at 12 $\mathrm{mg} \cdot \mathrm{kg}^{-1} \cdot \mathrm{h}^{-1}$ for the first $30 \mathrm{~min}, 9 \mathrm{mg} \cdot \mathrm{kg}^{-1} \cdot \mathrm{h}^{-1}$ for the next $30 \mathrm{~min}$, and $6 \mathrm{mg} \cdot \mathrm{kg}^{-1} \cdot \mathrm{h}^{-1}$ thereafter. A syringe infusion pump (Medfusion Systems Inc. Model \# 1001) was used for all infusions. Patients 11 through 30 in the propofol group received $9 \mathrm{mg} \cdot \mathrm{kg}^{-1} \cdot \mathrm{h}^{-1}$ propofol for the first $30 \mathrm{~min}$ and $6 \mathrm{mg} \cdot \mathrm{kg}^{-1} \cdot \mathrm{h}^{-1}$ thereafter. Vecuronium bromide was used to maintain neuromuscular blockade. In order to allow the patients to show signs of light anaesthesia twenty to twenty-five per cent of the twitch response was maintained as assessed with a peripheral nerve stimulator. ${ }^{6}$ Additional analgesia was provided with fentanyl $(0.05 \mathrm{mg}$ boluses $)$ and the anaesthetic level was adjusted with propofol boluses $(0.25$ $\mathrm{mg} \cdot \mathrm{kg}^{-1}$ ) or by adjusting the enflurane concentration to maintain haemodynamic variables within 30 per cent of awake measurements. The aim was to use the lowest enflurane concentration possible. At the end of surgery, glycopyrrolate $0.4 \mathrm{mg}$ and neostigmine $2.0 \mathrm{mg}$ were given for reversal of the neuromuscular blockade. Postoperative analgesia was provided with IV morphine, $5 \mathrm{mg}$ at a time, as needed.

Blood pressure was measured (Dynamap, model \# 1846P) once per minute for the first ten minutes and every five minutes thereafter. The ECG was monitored continuously. End-tidal carbon dioxide concentration and oxygen saturation were measured continuously to ascertain normal ventilation and oxygenation in all patients.

All recovery characteristics were assessed by a research nurse who was blinded to the treatment group. Duration of anaesthesia is reported as the time from the start of propofol or thiopentone injection until the tracheal tube was removed. Patients' recovery from anaesthesia and surgery was assessed as early or intermediate. Early
TABLE I Overall quality of recovery

\begin{tabular}{ll}
\hline Good & $\begin{array}{l}\text { Rapid retum to consciousness and orientation with no } \\
\text { anaesthetic complications through the recovery raom } \\
\text { period }\end{array}$ \\
Adequate & $\begin{array}{l}\text { Fairly rapid retum to consciousness and orientation; } \\
\text { minor anaesthetic complications during the recovery } \\
\text { room period } \\
\text { Delayed recovery or prolonged somnolence or protracted } \\
\text { side effects from anaesthesia during recovery room period }\end{array}$ \\
\hline
\end{tabular}

recovery, i.e., the time between discontinuation of $\mathrm{N}_{2} \mathrm{O}$ to the time when the patient was awake and oriented with protected reflexes, was assessed by extubation time, responsiveness to commands, spontaneous eye opening, and orientation to time and place. Intermediate recovery, defined as the time from the end of early recovery until the patient met PACU discharge criteria, was evaluated by a trained nurse who was not aware of the anaesthetics given. Intermediate recovery was evaluated by a scoring system according to Aldrete and Kroulik ${ }^{7}$ which is based on the patient's activity, respiration, blood pressure, consciousness and colour. The score was assessed at 15 min intervals until the patient had a score of ten points. Overall quality of recovery, as evaluated by the research nurse, was assessed as good, adequate or poor (Table I). Emetic symptoms (nausea, retching and vomiting) were evaluated every 15 minutes in the PACU.

Prior to surgery, immediately before discharge from the PACU, at 24 hours and 48 hours after surgery, patients were asked to complete a visual analogue questionnaire (VAQ). The following items were presented: dizziness, nausea, vomiting, depression/sadness, blurred or double vision, drowsiness, hunger, headache, sore throat and ability to concentrate. Each item was followed by a 100

TABLE II Demographic characteristics and drug doses (mean \pm SD)

\begin{tabular}{lcc}
\hline Group & Propofol & Thiopentone-enflurane \\
\hline Fernale/male (n) & $30 / 0$ & $29 / 1$ \\
Age $(\mathrm{yr})$ & $41 \pm 13.0$ & $40 \pm 9.5$ \\
Weight $(\mathrm{kg})$ & $73 \pm 10.6$ & $71 \pm 14.4$ \\
Height $(\mathrm{cm})$ & $161 \pm 6.1$ & $160 \pm 8.9$ \\
Total dose of & & \\
$\quad$ propofol (mg) & $1383 \pm 374.2$ & \\
fentanyl $(\mu \mathrm{g})^{*}$ & $52 \pm 48$ & $33 \pm 37$ \\
vecuronium (mg) & $6.8 \pm 2.0$ & $6.1 \pm 1.5$ \\
Duration of anaesthesia (min) & $152 \pm 38.4$ & $162 \pm 44.3$ \\
Operation & & \\
$\quad$ hysterectomy & 21 & 19 \\
myomectomy & 3 & 2 \\
lysis of adhesions & 2 & 0 \\
other & 4 & 9 \\
\hline
\end{tabular}

"During maintenance of anaesthesia 


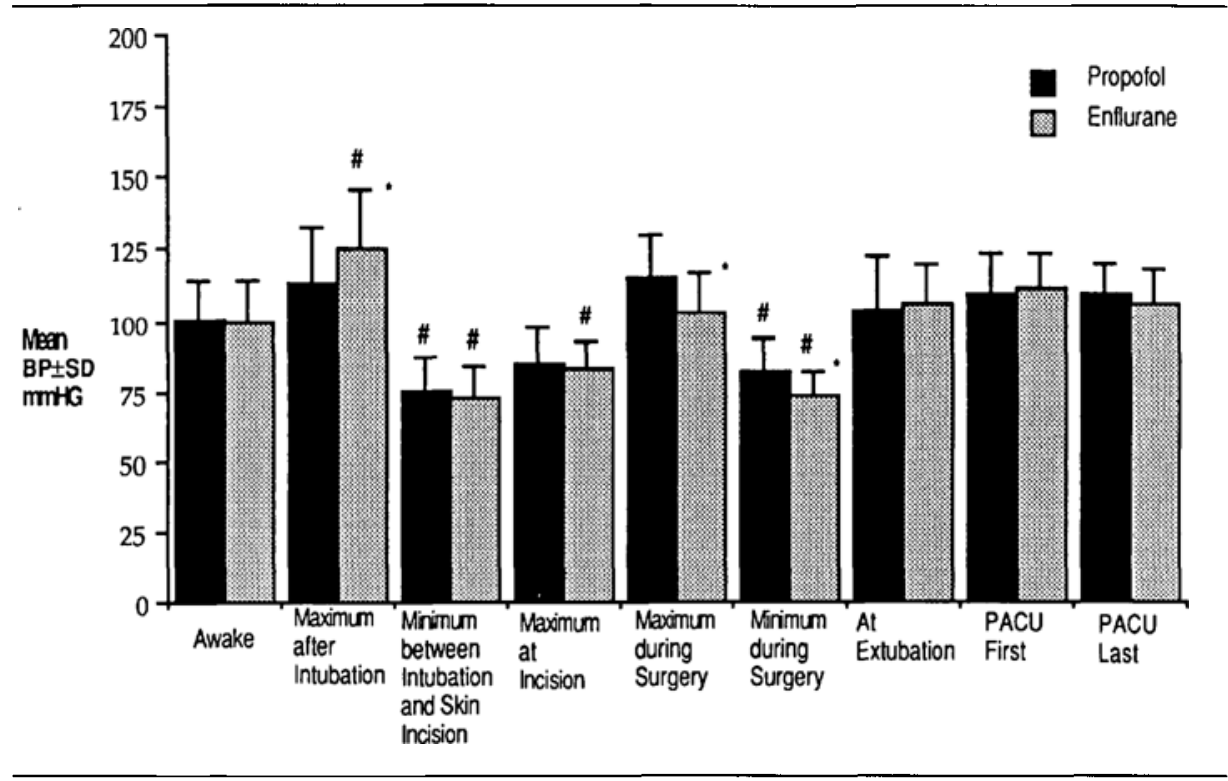

FIGURE 1 Mean arterial pressure prior to, during and after surgery under propofol or enflurane anaesthesia. All values expressed as mean $\left( \pm\right.$ SD). $P<0.05\left(^{*}\right)$ propofol vs enflurane. $P<0.05(\#)$ vs baseline.

$\mathrm{mm}$ line. One end of the line was marked "none" and the other, "a lot." Patients were instructed to cross the line at the place which best indicated how they felt about each item. Patients were also asked 24 and 48 hours after surgery if they had experienced any pain at the IV site. At this time nursing notes were reviewed to determine the amount of nausea and vomiting patients had had and any treatment prescribed for emetic symptoms.

Statistical analysis for continuous data was performed using analysis of variance followed by Scheffe's F-test. Chi-square test with continuity correction and MannWhitney $\mathrm{U}$ test were used for nonparametric variables.

\section{Results}

A total of 60 patients, most of whom were undergoing gynaecological laparotomies, were enrolled in the study. The treatment groups were demographically similar in terms of age, weight, ASA class, type and duration of surgery (Table II). No significant differences were found between the groups in the amounts of total fentanyl or vecuronium used.

Induction of anaesthesia was clinically satisfactory in all of the patients. Induction times, loss of eyelash reflex, and loss of consciousness were similar in both groups. Two patients in the propofol group and two in the enflurane group required an additional second dose (25 per cent of the first dose) to induce hypnosis. After the start of injection, the time for loss of consciousness was $38 \pm 6.3$ and $37 \pm 8.8 \mathrm{sec}$ (mean \pm SD), and the time for loss of eyelash reflex was $45 \pm 6.5$ and $43 \pm 8.3 \mathrm{sec}$ in the propofol and thiopentone-enflurane groups, respectively.

No involuntary movements were noted during induction in any of the patients. At the time of induction, three patients in the propofol group and one in the thiopentoneenflurane group complained of pain occurring at the IV site. Twenty-four hours postoperatively, two patients in the propofol group and three in the thiopentone-enflurane group complained of pain at their IV sites. No evidence of venous thrombosis or phlebitis was discovered in any patient within 48 hours of the surgery.

Systolic, diastolic and mean arterial blood pressures changed similarly throughout the study; only the mean arterial blood pressures (MAP) are reported here (Figure 1). There were no differences in the MAP or heart rate between the propofol and enflurane groups except following tracheal intubation when MAP was significantly lower $(P<0.05)$ after propofol induction. Following tracheal intubation mean arterial pressures were 114 per cent $(77-169, \pm 23.2)$ and 125 percent $(93-174, \pm 16.0)$ of the preoperative value in propofol and enflurane groups, 


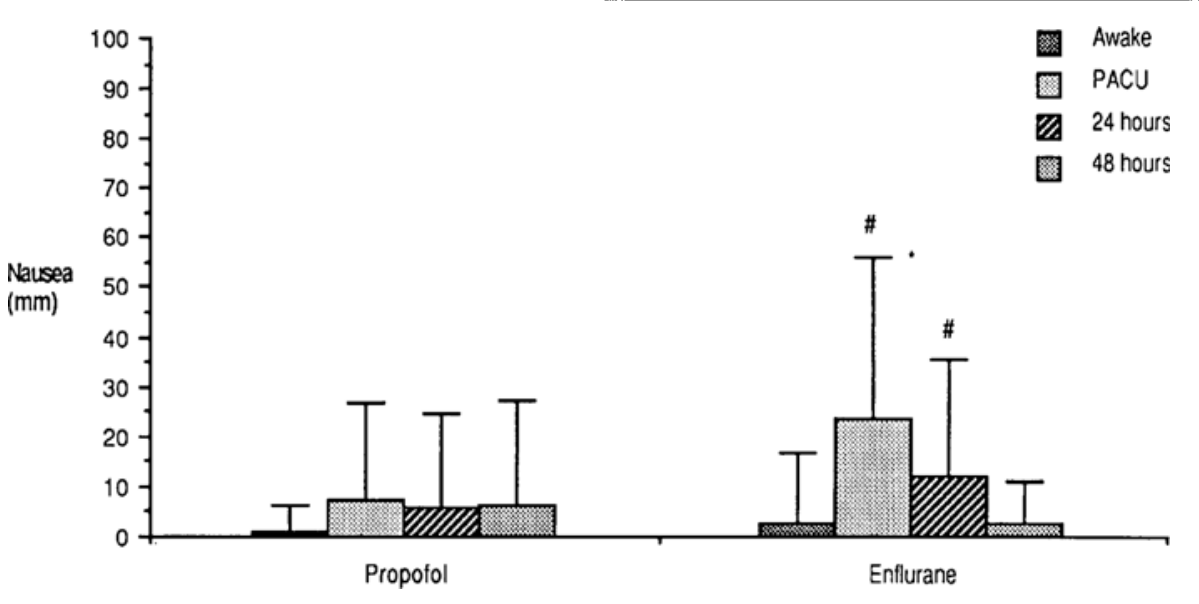

FIGURE 2 Visual Analogue Questionnaire: Nausea in each group prior to surgery, in PACU, 24 and 48 hours postoperatively. All values expressed in mm as mean $\left( \pm\right.$ SD). $P<0.05\left(^{*}\right)$ Propofol vs enflurane. $P<0.05$ (\#) vs baseline.

respectively (per cent of mean preoperative blood pressure, per cent range, $\pm S D$ ).

The times from discontimuation of $\mathrm{N}_{2} \mathrm{O}$ to extubation, eye opening, response to commands, orientation and discharge from the PACU were similar in both groups (Table III). There were no differences in the Aldrete score determined after arrival at the PACU. There was no correlation between the total dose of propofol used and the log transformed recovery and discharge times. The research nurse assessed quality of recovery as good in 16 , adequate in 13 and poor in one of the patients in the propofol group. Similarly, there were eight patients with good and 22 patients with adequate recovery in the enflurane group (propofol vs enflurane $P<0.065$ ). One patient in the propofol group and five in the enflurane group would not request the same anaesthetic method for their next surgery.

The amount of morphine needed for postoperative pain relief was similar in both groups (mean $\pm \mathrm{SD} ; 9 \pm 6$ and

TABLE III Early recovery (mean \pm SD)

\begin{tabular}{lcc}
\hline Group & Propofol & $\begin{array}{c}\text { Thiopentone- } \\
\text { enflurante }\end{array}$ \\
\hline $\mathrm{N}_{2} \mathrm{O}$ off to & & \\
$\quad$ Extubation (min) & $4.8 \pm 4.1$ & $3.8 \pm 2.3$ \\
Response to commands (min) & $4.6 \pm 4.5$ & $5.2 \pm 2.9$ \\
Spontaneous eye opening (min) & $5.8 \pm 6.2$ & $6.1 \pm 3.1$ \\
Orientation (min) & $12.6 \pm 44.6$ & $14.3 \pm 15.2$ \\
Discharge from PACU (min) & $128.4 \pm 44.6$ & $116 \pm 42.3$ \\
\hline
\end{tabular}

$7 \pm 4 \mathrm{mg}$ for propofol and enflurane groups, respectively). The thiopentone-enflurane group had significantly $(P<$ $0.01)$ more nausea and vomiting in the PACU than the propofol group (Table IV). None of the patients in the propofol group and five patients in the thiopentoneenflurane group required droperidol in the PACU. At 24 and 48 hours there were no differences in the number of patients having emesis between the groups. When emesis was assessed using the VAQ the thiopentone-enflurane group had significantly $(P<0.05)$ more nausea in the PACU and at 24 hours than they had preoperatively and significantly $(P<0.05$, VAQ) more nausea than the propofol group in the PACU (Figure 2).

When compared with baseline or to the propofol group, the patients in the enflurane group were significantly $(P<0.05)$ more dizzy in the PACU (Figure 3). Results for the other questions answered in the VAQ are listed in table $\mathrm{V}$. The propofol group experienced significantly $(P<0.05)$ less drowsiness, depression/sadness and hunger than the thiopentone-enflurane group. No differences were noted between the groups in terms of sore throat, headache or blurred or double vision.

\section{Discussion}

This study demonstrates that when propofol anaesthesia is administered by continuous infusion for operations lasting 1.5-2 hours no major differences can be expected in terms of rapidity of recovery or discharge times from PACU when compared with thiopentone-enflurane anaes- 


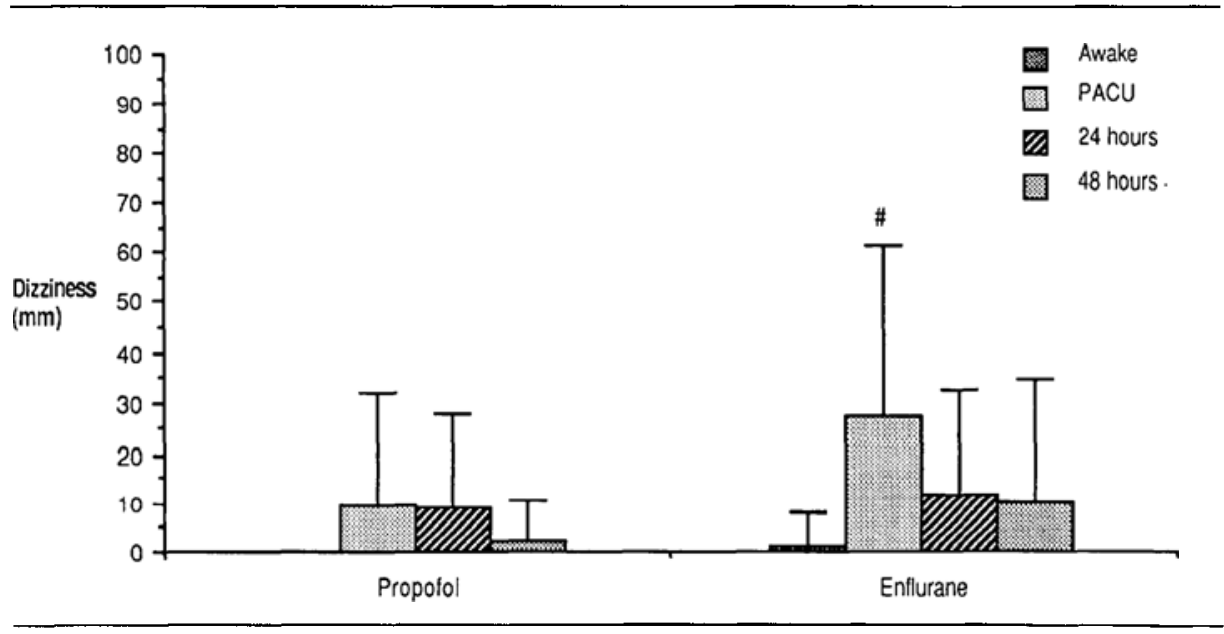

FGURE 3 Visual Analogue Questionnaire: Dizziness in each group prior to surgery, in PACU, 24 and 48 hours postoperatively. All values expressed in mm as mean $( \pm \mathrm{SD}) . P<0.05\left(^{*}\right)$ Propofol vs enflurane. $P<0.05(\#)$ vs baseline.

thesia. Long propofol-nitrous oxide anaesthesia is, however, likely to be associated with fewer annoying outcome symptoms, e.g. nausea and vomiting, than comparable thiopentone-enflurane-nitrous oxide anaesthesia.

We chose a propofol induction dose of $2 \mathrm{mg} \cdot \mathrm{kg}^{-1}$ because, in previous studies, this dose produced anaesthesia in at least 95 per cent of premedicated patients. ${ }^{7}$ The infusion rate was reduced in the last 20 patients randomized to receive propofol because in another study' the minimum infusion rate required to suppress response to surgery was found to be $112 \mu \mathrm{g} \cdot \mathrm{kg}^{-1} \cdot \mathrm{min}^{-1}$. When the high and low infusion rate subgroups were compared there were no differences in any of the variables measured. Similarly, no differences were noted in the variables measured between the first ten and the last 20 patients randomized to receive enflurane. This warrants us to compare all the patients in the propofol group with those in the thiopentone-enflurane group.

TABLE IV Emesis after propofol or enflurane anaesthesia

\begin{tabular}{lll}
\hline Group & Propofol $(n=30)$ & $\begin{array}{l}\text { Thiopentone-enflurane } \\
(n=30)\end{array}$ \\
\hline No emesis & $23 \dagger$ & 11 \\
Emesis overall & 7 & 19 \\
Nausea & 6 & 12 \\
Retching & 0 & 3 \\
Vomiting & 1 & 4 \\
Required droperidol & $0^{*}$ & 5 \\
\hline
\end{tabular}

$* P<0.05$ and $+P<0.01$ vs thiopentone-enflurane.
The haemodynamic responses to induction and maintenance of anaesthesia with propofol or thiopentoneenflurane were comparable and satisfactory. In the propofol group, however, the cardiostimulatory response to laryngoscopy and intubation was more effectively attenuated than in the thiopentone-enflurane group. This

TABLE V Visual analogue questionnaire ( $\mathrm{mm}$, mean \pm SD)

\begin{tabular}{lrr}
\hline Group & Propofol & Thiopentone-enflurane \\
\hline $\begin{array}{l}\text { Drowsiness } \\
\text { baseline }\end{array}$ & $4 \pm 12.2$ & $5 \pm 10.5$ \\
PACU & $35 \pm 30.6$ & $45 \pm 27.1$ \\
24 hours & $20 \pm 21.9$ & $24 \pm 29.8$ \\
48 hours & $4 \pm 11.3^{*}$ & $14 \pm 22.8$ \\
Ability to concentrate & & \\
baseline & $87 \pm 19.2$ & $88 \pm 21.5$ \\
PACU & $82 \pm 23.7$ & $74 \pm 20.6$ \\
24 hours & $88 \pm 16.7$ & $84 \pm 19.2$ \\
48 hours & $93 \pm 10.5$ & $89 \pm 16.6$ \\
Depression/sadness & & \\
baseline & $17 \pm 27.4$ & $21 \pm 30.1$ \\
PACU & $3 \pm 17.9$ & $6 \pm 18.5$ \\
24 hours & $1 \pm 4.4^{*}$ & $8 \pm 18.5$ \\
48 hours & $1 \pm 3.5^{*}$ & $8 \pm 16.8$ \\
Hunger & & \\
baseline & & $40 \pm 40.8$ \\
PACU & $41 \pm 38.3$ & $41 \pm 40.6$ \\
24 hours & $14 \pm 29.5^{*}$ & $31 \pm 35.8$ \\
48 hours & $19 \pm 34.6^{*}$ & $38 \pm 33.3$ \\
\hline
\end{tabular}

$* P<0.05$ vs thiopentone-enflurane. 
is in agreement with earlier studies by Valanne and Korttila ${ }^{8}$ who found that heart rate increase after tracheal intubation was attenuated more after propofol induction than after methohexitone induction of anaesthesia.

In contrast to other studies, ${ }^{10,11}$ in which a $30-36$ per cent incidence of pain on injection was associated with propofol, only three patients in the propofol group and one patient in the thiopentone-enflurane group complained of pain at the IV site during induction. These differences may be secondary to differences in induction technique. Weightman et al ${ }^{10}$ used propofol $2.5 \mathrm{mg}$. $\mathrm{kg}^{-1}$, and the duration of injection was $20 \mathrm{sec}$. Coates et al. " do not state the duration of injection, and their IV was used only for propofol infusion. Our patients received fentanyl prior to propofol injection. In addition, no patient in this study had phlebitis or thrombosis at the site of injection.

Previous studies ${ }^{10,12-15}$ which have compared early recovery between propofol and other anaesthetic agents in surgical procedures of short duration, show that recovery is faster after propofol than after other anaesthetic techniques. For example, when anaesthesia induced and maintained with propofol was compared with thiopentone! isoflurane anaesthesia in ambulatory surgery, patients anaesthetized with propofol met criteria for discharge home approximately one hour earlier than patients anaesthetized with thiopentone/isoflurane. ${ }^{15}$ Price, ${ }^{16}$ however, who used continuous propofol infusion, found no significant differences in the recovery times with propofol vs enflurane/ $\mathrm{N}_{2} \mathrm{O}$ anaesthesia. In order to control the residual effect of the anaesthetic to the recovery, early recovery times in the study reported here were from the time $\mathrm{N}_{2} \mathrm{O}$ was turned off. Recently Doze et al. ${ }^{17}$ reported no differences in early recovery times after propofol vs thiopentone/isoflurane anaesthesia. However, in spite of similar duration of anaesthesia and similar total dose of propofol, their patients recovered substantially more slowly from the anaesthestic than the patients in this study (response to command 10 vs 4.3 , spontaneous cye opening 8 vs 5.2 and orientation 20 vs 12.8 , mean time in min after discontinuation of $\mathrm{N}_{2} \mathrm{O}$ ). Doze et al. ${ }^{17}$ do not specify the type of surgery performed; their patients had a mean age of 46 years and 80 per cent of them were designated ASA physical status III. In the study reported here all those in the propofol group were ASA class I or II patients, had gynaecological laparotomy, and a mean age of 39 years. These factors may have influenced the early recovery times. Our recovery times are comparable with those for the group in the study by Doze et al. ${ }^{17}$ in which patients had shorter (76 min) non-major ambulatory surgery under propofol- $\mathrm{N}_{2} \mathrm{O}$ anaesthesia. One explanation for the faster recovery after propofol versus other intravenous or inhaled anaesthetics following short procedures but not after procedures lasting two to four hours is that administration of larger doses of propofol will change the pharmacokinetic and pharmacodynamic behaviour of the drug and will make it clinically longer acting.

Emetic symptoms postoperatively are distressing to the patient and may interfere with discharge from the PACU. ${ }^{18}$ Discharge times and "home-readiness" have been emphasized in outpatients, but these may be equally important for inpatients in order to discharge them from PACU at the earliest possible time and therefore decrease hospital costs (and in some cases charges). Postoperative nausea and vomiting are influenced by many factors, such as the patient's age, sex, the nature and duration of operation, the type of anaesthesia and the use of opioid analgesics. These variables were standardized as far as possible under the clinical conditions of our study. In operations of short duration, patients undergoing minor gynaecologic surgery and anaesthetized with propofol had less emetic sequelae than patients who have been anaesthetized with methohexitone or enflurane. ${ }^{16,19}$ Our results show that a long propofol anaesthetic is also associated with less emesis than comparable inhalational anaesthesia using enflurane.

It is concluded that long propofol anaesthesia is not associated with faster recovery or earlier discharge of inpatients from the recovery room than comparable enflurane anaesthesia but propofol is likely to be associated with less dizziness and emesis than enflurane anaesthesia.

\section{Acknowledgments:}

We would like to thank Mary Hendren, R.N. and Marjorie Robert, C.R.N.A. for their superb assistance.

\section{References}

1 Spelina KR, Coates DP, Monk CR, Prys-Roberts C, Norley I, Turtle MJ. Dose requirements of propofol by infusion during nitrous oxide anaesthesia in man. $\mathrm{Br}$ J Anaesth 1986; 58: 1080-4.

2 Kay NH, Sear JW, Uppington J, Cockshott I, Douglas $E J$. Disposition of propofol in patients undergoing surgery. A comparison in men and women. Br J Anaesth 1986; 58: 1075-9.

3 Gepts E, Jonckheer K, Maes V, Sonck W, Camu F. Disposition kinetics of propofol during alfentanil anaesthesia. Anaesthesia 1988; 43(Supplement): 8-13.

4 Cockshott ID, Briggs LP, Douglas EJ. Pharmacokinetics of propofol in female patients. Studies using single bolus injections. Br J Anaesth 1987; 59: 1103-10. 
5 Youngberg $J A$, Texidor $M S$, Smith DE. A comparison of induction and maintenance of anesthesia with propofol to induction with thiopenthal and maintenance with isoflurane. Anesth Analg 1987; 66: \$1-\$191.

6 Ali HH, Savarese JJ. Monitoring of neuromuscular function. Anesthesiology 1976; 45: 216-22.

7 Aldrete JA, Kroulik $D$. A postanesthetic recovery score. Anesth Analg 1970; 49: 924-34.

8 Valanne J, Korttila K: Comparison of methohexitone and propofol ('Diprivan') for induction of enflurane anaesthesia in outpatients. Postgrad Med J 1985; 61 (Suppl 3): 138-43.

9 Rolly $G$, Versichelen $L$, Herrwgods $L$. Cumulative experience with propofol as an agent for the induction and maintenance of anaesthesia. Postgrad Med J 1985; 61 (Supplement 3): 96-100.

10 Weightman WM, Zacharias $M$. Comparison of propofol and thiopentone anaesthesia (with special reference to recovery characteristics). Anaesth Intensive Care 1987; 15; 389-93.

11 Coutes DP, Monk CR. Prys-Roberts C, Turtle M. Hemodynamic effects of infusions of the emulsion formulation of propofol during nitrous oxide anesthesia in humans. Anesth Analg 1987; 66: 64-70.

12 McDonald NJ, Mannion D. Lee P, O'Toole P, O'Boyle C, Keane $P K$. Mood evaluation and outpatient anaesthesia. Anaesthesia 1988; 43(Supplement); 68-9.

13 Kortila K, Faure E, Apfelbaum J, Ekdawi M, Prunskis J, Roizen $M$. Recovery from propofol versus thiopentalisoflurane in patients undergoing outpatient anesthesia. Anesthesiology 1988; 69: A564.

14 Vinik HR, Shaw B, MacKrell T, Hughes $G$. A comparative evaluation of propofol for the induction and maintenance of general anesthesia. Anesth Analg 1987; 66: S184.

15 Sampson IH, Plosker H, Cohem M, Kaplan JA: Comparison of propofol and thiamylal for induction and maintenance of anaesthesia for outpatient surgery. $\mathrm{Br} \mathrm{J}$ Anaesth 1988; 61: 707-11.

16 Price $M L$. Comparison of total intravenous anaesthetic technique using propofol infusion, with an inhalation technique using enflurane for day case surgery. Anaesthesia 1988; 43: 84-7.

17 Doze VA, Shafer A, White PF. Propofol-nitrous oxide versus thiopentone-isoflurane-nitrous oxide anesthesia for general anesthesia. Anesthesiology 1988; 69: 63-71.

18 Korttila $K$. Practical discharge criteria. Problems in Anesthesia 1988: 2: 144-51.

19 McCollum JSC, Milligan KR, Dundee JW. The antiemetic action of propofol. Anaesthesia 1988; 43: 239-40.

\section{Résumé}

Nous avons comparé le propofol et une combinaison de thiopental-enflurane quant à l'induction, l' hémodynamie et le réveil de 60 patientes randomizées de classe ASA I-II, candidates pour lo plupart à une laparotomie d' ordre gynécologique. Les patientes recevaient soit un bolus de $2 \mathrm{mg} \cdot \mathrm{kg}^{-1}$ suivi d' une infusion de propofol $(n=30)$, soit $4 \mathrm{mg} \cdot \mathrm{kg}^{-1}$ de thiopental suivi de 0,5 \2,0\% d'enflurane $(n=30)$. A toutes, nous avons injecté $1,5 \mu \mathrm{g} \cdot \mathrm{kg}^{-1}$ de fentanyl quatre minutes avant l'induction et donné 66 pour cent de protoxyde d'azote d̀ partir d'une minute post-intubation. Les deux groupes étaient comparables quant aux autres médicaments reçus et avaient des profils hémodynamiques semblables sauf après l' intubation de la trachée où la pression artérielle moyenne était plus basse avec le propofol $(P<0,05)$. Comparé au groupe enflurane, le groupe propofol eu moins de vomissements au réveil $(P<0,01)$ et moins $d^{2}$ étourdissements, de dépression, de tristesse et de faim en post-opératoire selon une échelle visuelle analogique $(P<$ $0,05)$. Donc, selon ces indicateurs non vitaux quoique utiles, les patientes se portent mieux lorsque qu' on utilise du propofol au lieu de thiopental-enflurane pour des interventions intraabdominales relativement longues. 